\title{
Tolerance to the Effects of Daily Nicotine on Rat Bar Pressing Behavior for Water Reinforcement'
}

\author{
EDWARD F. DOMINO AND MICHAEL P. LUTZ \\ Department of Pharmacology, University of Michigan, Ann Arbor, Michigan 48104
}

(Received 15 May 1973)

\begin{abstract}
DOMINO, E. F. AND M. P. LUTZ. Tolerance to the effects of daily nicotine on rat bar pressing behavior for water reinforcement. PHARMAC, BIOCHEM. BEHAV. 1(4) 445-448, 1973.-The effects of daily nicotine tartrate given IP in a dose of $0.25 \mathrm{mg} / \mathrm{kg}$ twice a day for 15 days was studied on bar pressing behavior for water reinforcement in the rat. A modified $\mathrm{FR}_{15}$ schedule was used. Nicotine injections caused an initial disruption of bar pressing behavior with rapid tolerance development. Antidiuretic hormone (5-10 units $/ \mathrm{kg}, \mathrm{SC}$ ) administration also suppressed water drinking behavior after an initial latency in contrast to the effects of nicotine. It is concluded that tolerance occurs to daily nicotine administration.
\end{abstract}

Nicotine Bar pressing behavior Water reinforcement Tolerance development

ALTHOUGH a great deal is known about the acute pharmacology of nicotine and tobacco smoking, relatively little is known about the behavioral effects of chronic nicotine administration. This void exists in spite of enormous sums of money spent by the public in maintaining their tobacco smoking habits. Recently Goldstein and his associates have reported some remarkable neuropsychopharmacological effects of chronic nicotine administration $[1,4]$. Rabbits given $200 \mu \mathrm{g} / \mathrm{kg}$ of nicotine SC daily for 3 weeks show a shift in EEG activation from the reticular formation to the hippocampus [1]. These investigators suggested that such a change should result in "incentive-oriented arousal" vis a vis "drive oriented arousal" according to Routtenberg's hypothesis [6]. Chronic nicotine base in a dose of $100 \mu \mathrm{g} / \mathrm{kg}$ given SC TID for 4 weeks to rats improved performance on an attention task [4]. Animals were trained to respond with a single lever press to a very short, variably presented stimulus for food reinforcement, but also to inhibit inappropriate responses. Chronic nicotine treatment caused a reduction of inappropriate responding in comparison to chronic saline administration.

Schechter and Rosecrans [8] showed that chronic administration produced tolerance to nicotine $(0.4 \mathrm{mg} / \mathrm{kg} \mathrm{SC}$, $4 \mathrm{x}$ daily) used as a discriminative cue in a discrimination task. After 5 days, the rats were performing no better than a chance level in a $T$ maze. If the animal chose the correct arm after nicotine, it was rewarded with milk. An incorrect response was punished by an electric shock.

In the present study we report the effects of chronic daily nicotine given to rats bar pressing on a water reinforcement $F_{R_{1}}$, schedule. This behavior is dramatically suppressed by acute nicotine. It was important to determine if tolerance and a possible rate facilitating effect could be demonstrated with chronic administration on a nonpunished operant behavior.

\section{METHOD}

The animals were six male Holtzman albino rats that were given free access to food, but were water deprived. The rats were trained to bar press for water. Before given any drugs, they were run daily except weekends, until stable performance was observed. The schedule was a fixed ratio of 15 presses $\left(F R_{15}\right)$, that is the 15 th bar press in the presence of a yellow cuelight would result in a presentation of a $4 \mathrm{sec}$ water reinforcement. The yellow light was actuated on a variable interval with an average of $20 \mathrm{sec}$ between. The light stayed on until the fifteenth bar press was made. There was also a $2 \mathrm{sec}$ delay between the fifteenth bar press and the reinforcement. The animals were run in a modified picnic ice chest that had a false wall dividing the chest approximately in half. The wall contained a bar (approximately $20 \mathrm{~g}$ pressure to activate), a yellow cue light, a white house light and a round hole for the water dipper. The animals were run Monday thru Friday for 45 min each and given $1 / 2 \mathrm{hr}$ free access to water after their individual run.

Nicotine tartrate (obtained from the University of Michigan Hospital Pharmacy) was adjusted to a $\mathrm{pH}$ of 7 . It was

\footnotetext{
'Supported in part by a grant from the Council for Tobacco Research, U.S.A.
} 
given IP in a dose of $0.25 \mathrm{mg} / \mathrm{kg}$ as base twice daily to each rat. The first injection was given immediately before the animal was tested for the day. The second dose was given before the animal was placed in the home cage for the evening. Animals were not run on the weekends, but were still injected with nicotine once in the morning and once in the late afternoon. They were given free access to water on the weekend up until $24 \mathrm{hr}$ prior to the first run on Monday.

\section{RESULTS}

The data are reported in mean responses per min during the activation of the cuelight for 5 rats. Rat 5 was excluded because he exhibited a marked hypersensitivity to nicotine which was not apparent in the other animals as seen in Table 1. The effects of daily nicotine tartrate $0.25 \mathrm{mg} / \mathrm{kg} \mathrm{IP}$ twice a day for 15 days on bar pressing behavior for water reinforcement for one rat (No. 6) are shown in Fig. 1. When the animal was trained, it emitted reproducible rates of bar pressing on the $F R_{15}$ schedule as described above. The cumulative record on Day 0 before nicotine treatment is shown for a $45 \mathrm{~min}$ period. After $0.25 \mathrm{mg} / \mathrm{kg}$ of nicotine IP, bar pressing behavior was suppressed for about $35 \mathrm{~min}$ the first day. After daily nicotine BID, tolerance to its behavioral suppressing effects was observed which was marked by the fifteenth day. However, even after 15 days of treatment slight suppression of bar pressing behavior was still evident for a few minutes. In contrast, $0.9 \%$ (saline) had no significant effect. No increase in bar pressing was observed after nicotine.
The mean bar pressing rate $/ \mathrm{min}$ is given in Table 1 for all experimental days. It can be noted that nicotine tartrate in a dose of $0.25 \mathrm{mg} / \mathrm{kg} \mathrm{IP}$, caused a marked suppression of responding on Day 1 with gradual tolerance development. The unexpected increase on Day 2 was caused by Rat No. 2 who responded this one time only at an exceptionally high rate (see Table 1 ).

Inasmuch as nicotine releases antidiuretic hormone from the posterior pituitary, doses of 5 and 10 units $/ \mathrm{kg}$ were given SC. A dose related decrease in bar pressing behavior was observed, but it differed considerably from that of nicotine in its delayed onset of effect (Fig. 1).

\section{DISCUSSION}

It is well known that tolerance occurs to many of the pharmacological effects of nicotine. However, the details of schedules of dosage, time interval between injections, total duration of treatment and behavioral effects are important variables which need much more study. It is commonly assumed that optimal conditions for tolerance development include a high blood level $24 \mathrm{hr}$ a day for many weeks [7]. The brain content of nicotine given $\mathrm{SC}$ reaches a peak within 15-20 $\mathrm{min}$ and then slowly declines over a period of hours [5]. Hence, a BID schedule of nicotine injection would not be expected to maintain a high brain level of nicotine. Nevertheless, a high degree of tolerance to the behavioral depressant effects of nicotine was observed in the present study. The tolerance to nicotine observed in this study appears to be different from that described by

TABLE 1

EFFECTS OF DAILY NICOTINE ON BAR PRESS RATES FOR WATER REINFORCEMENT IN THE RAT

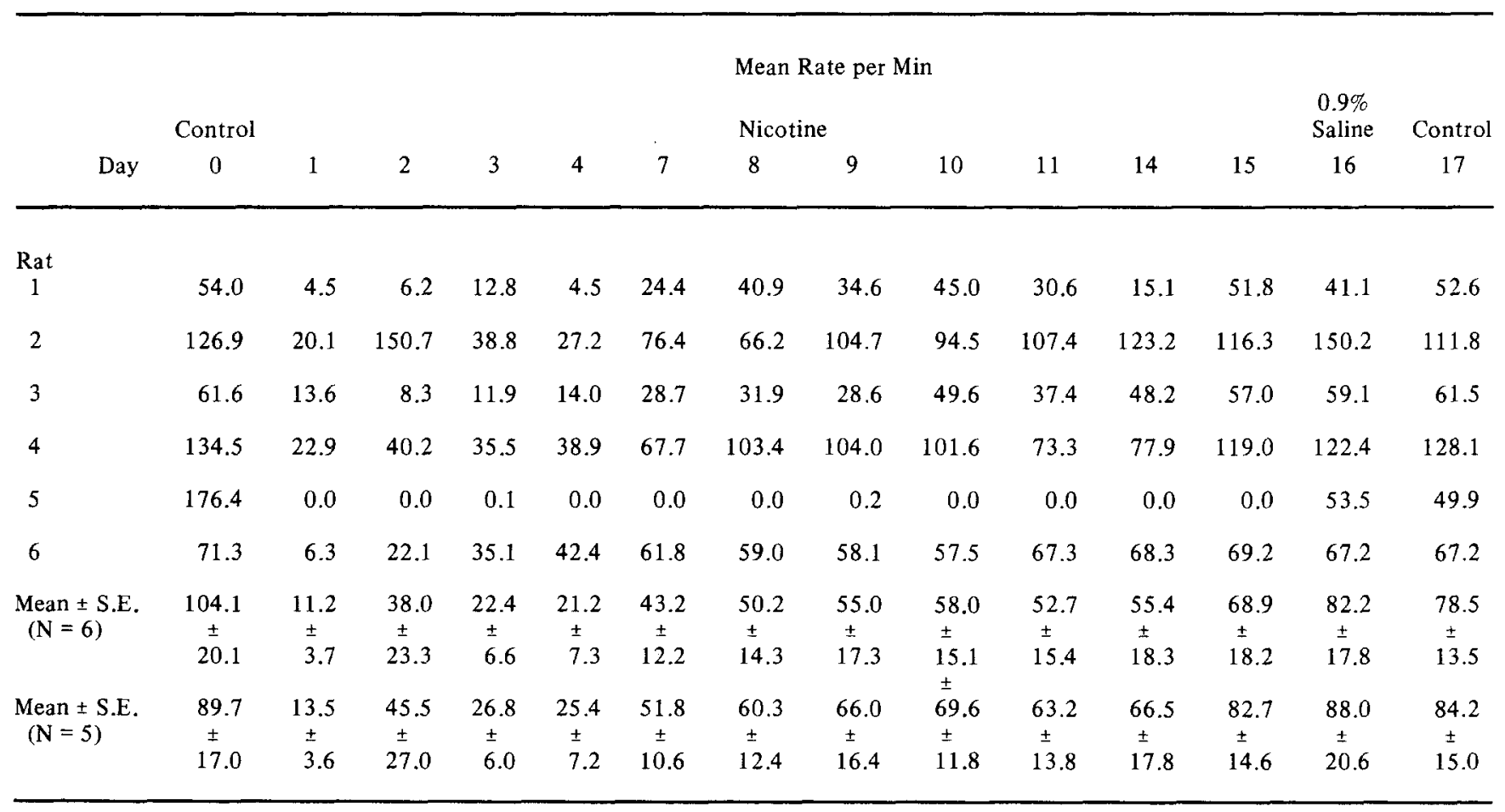

Nicotine was given bid $0.25 \mathrm{mg} / \mathrm{kg}$ in the morning and afternoon. Immediately after the morning injection each rat was run for $45 \mathrm{~min}$ in the behavioral situation. 

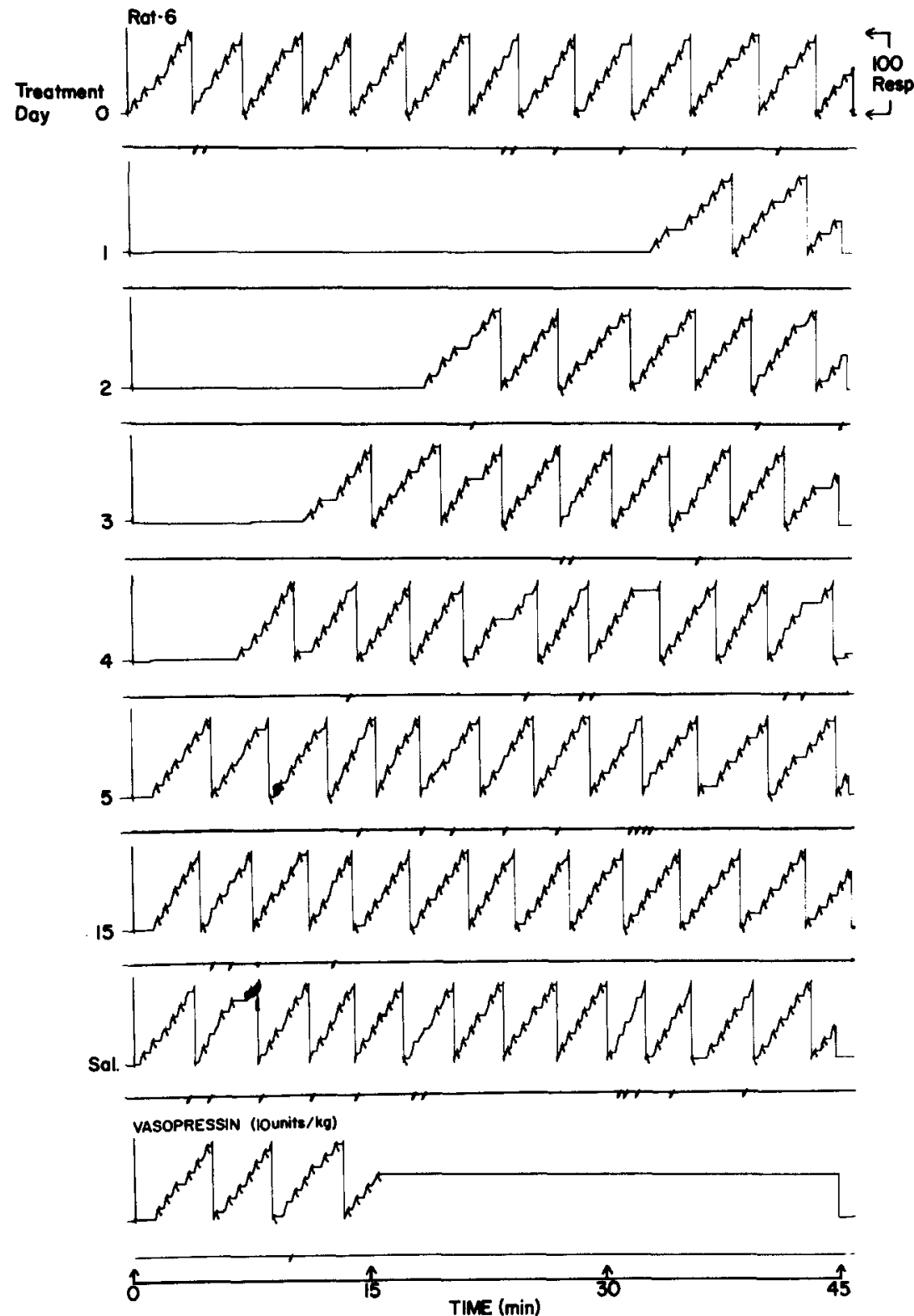

FIG. 1. Cumulative record of an individual rat showing the effects of daily nicotine on bar pressing behavior for water reinforcement on a $\mathrm{FR}_{1 \mathrm{~s}}$ schedule.

Schechter and Rosecrans [8]. The latter observed tolerance to a drug-induced state dependent behavioral effect. The role of behavioral vs. pharmacologic tolerance in the effects of nicotine must be studied further.

It should be pointed out that nicotine causes the release of antidiuretic hormone [2,3] and that this might reduce the animal's drive for water reinforcement. To test this possibility, we gave 5 and 10 units $/ \mathrm{kg}$ of antidiuretic hormone (vasopressin) SC immediately prior to the session. After approximately $15 \mathrm{~min}$ the rats stopped pressing for water. If the effects of nicotine on antidiuretic hormone release were the critical action, one would expect the rats not to press for the entire session. Since they resumed pressing after approximately $30 \mathrm{~min}$ on Day 1 of the nicotine ad- ministration, one can assume that the antidiuretic hormone release probably was not responsible for the initial rate suppressing effects of nicotine. Nevertheless, future research on the behavioral effects of this hormone are clearly indicated for it is unclear why it should suppress bar pressing in the first place. Perhaps it does reduce the animal's drive for water reinforcement as was postulated.

The relevance of the present finding of tolerance to nicotine given twice daily to the rat to chronic daily tobacco smoking in man is of obvious interest. It is known that some of the unpleasant effects of smoking tobacco by the novice are not experienced in the chronic user. Perhaps a similar phenomenon is occurring in the rat. 


\section{REFERENCES}

1. Bhattacharya, I. C. and L. Goldstein. Influence of acute and chronic nicotine administration of intra- and inter-structural relationships of the electrical activity in the rabbit brain. Neuropharmacology 9: 109-118, 1970.

2. Larson, P. S., H. B. Haag and H. Silvette. Tobacco: Experimental and Clinical Studies. Baltimore: Williams and Wilkins Co., 1961, p. 932.

3. Larson, P.S. and H. Silvette. Tobacco: Experimental and Clinical Studies. Suppl I. Baltimore: Williams and Wilkins Co., 1968 , p. 803.

4. Nelson, J. M. and L. Goldstein. Improvement of performance on an attention task with chronic nicotine treatment in rats. Psychopharmacologia 26: 347-360, 1972.
5. Rosecrans, J. A. and M. D. Schechter. Brain area nicotine levels in male and female rats of two different strains. Archs int. Pharmacodyn. Thér. 196: 46-54, 1972.

6. Routtenberg, A. The two-arousal hypothesis: Reticular formation and limbic system. Psychol. Rev. 75: 51-80, 1968.

7. Seevers, M. H. and G. A. Deneau. Phsyiological aspects of tolerance and physical dependence. In: Physiological Pharmacology, edited by W. S. Root and F. G. Hofmann. New York: Academic Press, 1963, pp. 565-640.

8. Schechter, M. D. and J. A. Rosecrans. Behavioral tolerance to an effect of nicotine in the rat. Archs int. Pharmacodyn. Ther. 195: $52-56,1972$. 